\title{
Comparative Genomic Hybridisation Arrays: High-Throughput Tools to Determine Targeted Therapy in Breast Cancer
}

\author{
David S.P. Tan Jorge S. Reis-Filho \\ Molecular Pathology Team, The Breakthrough Breast Cancer Research Centre, Institute of Cancer Research, \\ London, UK
}

\section{Key Words}

Comparative genomic hybridisation $\cdot$ Breast cancer •

Microarrays $\cdot$ Molecular genetics $\cdot$ Amplification

\begin{abstract}
Microarray-based comparative genomic hybridisation (aCGH) is contributing to the molecular characterisation of solid malignancies. This technique provides tremendous opportunities for translational research by facilitating detailed analysis of entire cancer genomes in a single experiment with unprecedented resolution. Apart from providing data to help catalogue the molecular genetic profiles of breast cancers and breast cancer cell lines, aCGH has also proven to be a useful technique for the identification of novel therapeutic targets. However, aCGH alone does not provide all lines of evidence required for the identification of 'amplicon drivers' and 'druggable targets'. This can be more effectively achieved by integrating data from aCGH, expression profiling and RNA interference experiments. In this review, we discuss the techniques available for aCGH analysis and possible approaches for using aCGH as a tool for the identification of novel therapeutic targets.

Copyright $\odot 2008$ S. Karger AG, Basel
\end{abstract}

\section{Introduction}

In the management of cancer, surgery, radiotherapy and chemotherapy remain the main modalities of treatment, particularly for patients with solid tumours. However, the advent of therapies based on mechanisms that target critical molecular pathways of tumours has evoked considerable interest $[1,2]$. Oncogenes and tumour suppressor genes are critical for both cell proliferation and cell fate determination (differentiation, senescence and apoptosis), with cell type- and context-specific effects. Thus, overexpression of a specific oncogene can enhance proliferation in one cell type but induce apoptosis in another $[3,4]$. Cancer cells are often 'addicted to' (that is, physiologically dependent on) the continued activity of specific activated or overexpressed oncogenes (molecular drivers) for maintenance of their malignant phenotype [1-4]. Subsequently, as the tumour develops, clones harbouring the constitutively activated oncogene or amplified oncogene with corresponding mRNA and protein overexpression are positively selected. When these genes are switched off, the cells undergo proliferative arrest, differentiation and apoptosis $[1,2,5]-$ hence the concept of targeted therapy.

Where such molecular drivers exist in tumours, such as the $B C R-A B L$ translocation in Philadelphia chromosome-positive chronic myeloid leukaemia (CML) [6], targeted therapy in the form of monoclonal antibodies or

\section{KARGER \\ Fax +41613061234 \\ E-Mail karger@karger.ch}

www.karger.com
(C) 2008 S. Karger AG, Basel

$1015-2008 / 08 / 0752-0063 \$ 24.50 / 0$

Accessible online at:

www.karger.com/pat
Jorge Reis-Filho, MD, PhD, FRCPath

The Breakthrough Breast Cancer Research Centre

Institute of Cancer Research, 237 Fulham Road

London SW3 6JB (UK)

Tel./Fax +44 207153 5167, E-Mail Jorge.Reis-Filho@icr.ac.uk 
Table 1. Comparison of aCGH and other techniques for genetic analysis

\begin{tabular}{|c|c|c|c|c|c|c|c|c|}
\hline Technique & Polyploidy & Aneuploidy & $\begin{array}{l}\text { Copy number } \\
\text { silent } \mathrm{LOH}^{1}\end{array}$ & $\begin{array}{l}\text { Balanced } \\
\text { translocation }\end{array}$ & $\begin{array}{l}\text { Unbalanced } \\
\text { translocation }\end{array}$ & \multicolumn{3}{|c|}{ Amplification } \\
\hline SKY & + & + & - & + & + & + & + & - \\
\hline $\mathrm{LOH}$ & - & + & + & - & + & + & + & + \\
\hline $\mathrm{FISH} \mathrm{CISH}^{2}$ & + & + & - & + & + & + & + & + \\
\hline Oligonucleotide arrays & - & + & - & - & + & + & + & + \\
\hline SNP chips & $+^{3}$ & + & + & - & + & + & + & + \\
\hline MIP arrays & - & + & + & - & + & + & + & + \\
\hline Solexa sequencing & - & + & + & + & + & + & + & + \\
\hline
\end{tabular}

$\mathrm{LOH}=$ Loss of heterozygosity; HSR = homogenous staining regions; DM = double minutes; $\mathrm{DI}=$ distributed insertions; + = detectable; - = undetectable; SKY = spectral karyotyping; FISH = fluorescent in situ hybridisation; CISH = chromogenic in situ hybridisation; $\mathrm{CGH}=$ comparative genomic hybridisation; $\mathrm{SNP}=$ single nucleotide polymorphisms; $\mathrm{MIP}=$ molecular inversion probes.

${ }^{1}$ Mitotic recombination/gene conversion and endoreduplication.

${ }^{2} \mathrm{FISH}$ and $\mathrm{CISH}$ require specific probes mapping to the genomic region of interest, which has to be specifically targeted. CISH has the advantage of allowing a direct comparison between specific genetic abnormalities and morphological features of the cells.

${ }^{3}$ Triploid and tetraploid states can be identified based on the ' $\mathrm{B}$ allele' frequency plots.

small molecule inhibitors, like imatinib, have been shown to induce dramatic and sometimes durable clinical responses in patients with tumours harbouring these specific genetic alterations [2]. In the context of breast cancer, this principle of oncogene addiction is illustrated by the improved response rates and survival benefit observed in patients with HER2-positive breast cancers, where overexpression of HER2 is driven by HER 2 gene amplification in $>90 \%$ of cases, following anti-HER 2 antibody (trastuzumab) therapy [7].

The majority of common solid tumours have complex karyotypes comprised of multiple genomic abnormalities with extensive cytogenetic variability [8]. The high level of karyotypic complexity has made a systematic characterisation of chromosomal patterns in solid tumours difficult. Hence, whilst many potential targets have been postulated, critical molecular drivers remain elusive, making the development of targeted therapy much more challenging. In the past, one of the main limitations in the process of target identification was the lack of techniques that could help identify recurrent molecular genetic changes in tumours with remarkably complex karyotypes. In recent years, this obstacle has partly been overcome by the development of microarray-based comparative genomic hybridisation $(\mathrm{aCGH})$ technologies $[9$, 10] specifically designed to interrogate the tumour genome for the critical molecular genetic changes driving tumour growth and progression, including a rapid and detailed analysis of global genomic copy number changes in entire tumour genomes (table 1). Considerable progress has been made since the inception of this technology, and various high-resolution (that is, the distance between each DNA target represented on the array) genomic analysis array platforms, including tiling path bacterial artificial chromosome (BAC) arrays of up to approximately $50 \mathrm{~kb}$ resolution [11] and oligonucleotide arrays with a theoretical resolution of up to approximately $2 \mathrm{~kb}$ [12], are now available. Studies using this technology have led to new molecular classifications of tumours by comparing patterns of genetic changes $[13,14]$, improved understanding of tumourigenesis and tumour progression [1517], and the identification of novel putative molecular therapeutic targets [18-20]. Recently, new techniques that allow both quantitative and qualitative analysis of entire genomes have been developed (www.illumina.com) [21], further extending the potential for molecular genetic analysis and therapeutic target discovery using aCGHbased techniques.

Although progress has been made, and despite the significant swell of aCGH methodologies and data in recent years [10], significant challenges still exist before the promise of aCGH (and its derivatives) can be translated to the clinical reality of targeted therapy discovery. Microarray techniques are subject to considerable data vari- 
Table 2. Challenges for aCGH studies

\section{Sample related}

Sample type (e.g. FFPE vs. fresh-frozen tissue) and number

Tissue and intra-tumour heterogeneity

DNA yield and quality

DNA amplification bias

Links with clinical databases

Tumour-specific aberrations versus copy number polymorphisms

Platform related

Reliability and reproducibility

Availability

Cost

Quantity of DNA required for assay

Types of aberrations detected (e.g. allelic versus non-allelic informative platform)

Resolution

Analysis methods

Integration of results with those of other high-throughput methods

FFPE $=$ Formalin-fixed paraffin-embedded

ability, due in part to variations in methods of DNA extraction, probe labelling and hybridisation, the type of microarray platform used, the number and biological characteristics of samples analysed, the methods used for microarray and statistical analysis, and results validation [22]. Hence, a whole spectrum of methodological issues need to be addressed before the impact of aCGH on translational research can be fully realised (table 2).

\section{aCGH Platforms: Current State of Play and Beyond}

There is currently a plethora of different aCGH platforms available and it should be emphasised that at the moment, there is no ideal method for aCGH analysis. Most platforms may be obtained commercially, all of which have advantages and limitations that should be taken into account for study design (tables 1 and 2). Detailed reviews on the technical aspects of aCGH analysis have recently been published and the readers should refer to them for a comprehensive discussion of these technologies $[10,12,23]$. Two basic types of genomic array technology exist: ordered arrays or random arrays. Ordered arrays are manufactured by spotting (using pins) or synthesising individual probes in an organised pattern on a planar surface. Random arrays are constructed by first immobilising individual probes onto beads which are then pooled and assembled onto a patterned planar surface. This allows an average of approximately 30 replicates of each probe in the array. The identity of each bead is determined following hybridisation of specific labelled complements to the probe sequences on the bead. Currently, the majority of aCGH platforms are ordered arrays, with random bead arrays only commercially available from Illumina (http://www.illumina.com/).

Highly parallel sequencing technologies capable of providing both quantitative (copy number) and qualitative (gene sequence) information from entire tumour genomes in a matter of weeks rather than years have been developed, and are now commercially available (http:// www.illumina.com/morethansequencing/). This technology (see Solexa sequencing technology below) has the potential to become the blueprint for the next generation of comparative genomic analysis tools for therapeutic target discovery.

\section{cDNA Arrays}

Initial studies on genome-wide approaches to aCGH were performed using cDNA microarrays which were originally designed for expression profiling [24]. cDNA microarrays were initially used for aCGH analysis, as clone sets were readily available and, in theory, would allow a direct correlation between genomic deletions and amplifications. However, cDNA microarray analysis enables only the detection of aberrations in known genes and expressed sequence tags, since cDNA probes are only representative of expressed genes on a chromosome. The absence of intronic sequences also reduces the stability of the hybridisation dynamics, leading to cross-hybridisation and reduced sensitivity. In terms of maximal achievable resolution, cDNA arrays cannot compete with currently available alternatives and are rapidly becoming obsolete in aCGH studies.

\section{BAC Arrays}

BACs, P1-derived artificial chromosomes and yeast artificial chromosomes are large-insert genomic clones which have been widely used in aCGH studies $[12,23,25]$. BAC arrays are spotted, dual-channel platforms where test (tumour) and reference DNA are differentially labelled (for example, Cy3 vs. Cy5) before hybridisation onto the array. BAC probes vary in length from 100 to 200 $\mathrm{kb}$ and the resolution of each $\mathrm{BAC}$ array is defined by the number of unique probes it contains. The probe content of genome-wide BAC arrays range from a few hundreds to approximately 32,000 unique elements (tiling path array). Tiling path arrays (that is, arrays where each $\mathrm{BAC}$ 
overlaps with its contiguous BACs) provide a resolution of up to approximately $50 \mathrm{~kb}$, given that a genomic change can only be detected if it is sufficiently big to significantly change the hybridisation intensity in one of the channels (that is, change the red:green ratios). These platforms provide sufficiently intense signals for the detection of single-copy number changes, are able to accurately define the boundaries of genomic aberrations and, importantly, can be readily applied to DNA extracted from archival formalin-fixed paraffin-embedded (FFPE) tissue as well $[26,27]$. One of the main drawbacks with BAC arrays is that their availability from commercial sources is limited and its in-house production is both expensive and highly labour-intensive. In addition, as BAC probes are representative of the human genome, they will also contain repetitive sequences, which can lead to non-specific hybridisation. In order to prevent non-specific hybridisation to these repetitive sequences, Cot-1 DNA is often included in the hybridisation reaction, adding to the overall cost of the assay.

\section{Oligonucleotide Arrays}

Oligonucleotide array aCGH (OaCGH) platforms consist of single-stranded 25- to 85-mer oligonucleotide elements $[12,28]$. Different types of oligonucleotide arrays have different labelling and hybridisation protocols and can provide high-resolution copy number measurements [12]. There are 2 main types of oligonucleotide arrays: Single nucleotide polymorphism (SNP) arrays and non-SNP arrays. Non-SNP arrays include those available from Agilent Technologies (http://www.agilent.com/) and NimbleGen (http://www.nimbledgen.com) and are comprised of 60 - to 75-mer oligonucleotides with sitespecific sequences across the genome. SNP arrays, such as those available from Affymetrix (http://www.affymetrix.com/) and Illumina (http://www.illumina.com/) are comprised of oligonucleotides that correspond to SNPs along the human genome and were originally designed for use in linkage analysis and whole-genome genotyping. Hence, unlike BAC arrays, SNP arrays can also provide information regarding loss of heterozygosity and copy-neutral genetic anomalies such as uniparental disomy and mitotic recombination, in addition to allelic copy number changes.

The main limitations with OaCGH platforms are significantly lower signal intensities when compared to those obtained with BAC arrays, and higher probe to probe variation and sequence dependence of hybridisation in the arrays, due in part to greater variation in hybridisation dynamics. This is likely to be a function of probe length (oligonucleotide probes are approximately $100 \mathrm{~kb}$ shorter then BAC probes) and comparative genomic content, leading to higher variation in signal intensity for similar copy numbers. Lower signal intensities for each probe lead to higher levels of experimental variation/background noise, which render the identification of low-level gains and losses more difficult and the use of degraded DNA (such as that extracted from FFPE samples) challenging. Consequently, although theoretically affording a resolution as high as approximately $2 \mathrm{~kb}$, signals from several probes (approx. 3-10) need to be averaged before a call can be made. However, the resolution of these platforms can easily be improved by increasing the feature density (that is, the number of SNPs) in the array. Hence, an array with 500,000 SNPs per slide, allowing an averaging of 10 SNPs for each call, will allow a resolution of approximately $50 \mathrm{~kb}$. With the anticipated introduction of a 1,000,000 SNP array later this year, the effective resolution of OaCGH arrays may increase to as much as approximately $10-25 \mathrm{~kb}$.

\section{Molecular Inversion Probe Arrays}

Molecular inversion probes (MIPs) are single oligonucleotides with 2 flanking inverted recognition sequences that recognise and hybridise to specific genomic DNA sequences ranging from 41 to 61 bp in length (http:// www.affymetrix.com/technology/mip_technology.affx). Following probe hybridisation to target DNA, a single base pair gap exists in the middle of the 2 recognition sequences. This gap can either be an SNP or a nonpolymorphic nucleotide. The gap is enzymatically filled with an appropriate oligonucleotide resulting in the formation of a circularised probe that subsequently undergoes 'probe inversion', which enables the probe to be amplified. Crossreacted or unreacted probes are separated from the resulting circularised probe via an exonuclease reaction. Each MIP oligonucleotide has a unique sequence barcode tag which can be assayed via a tag microarray once it anneals to its specific complementary genomic sequence and is circularised [28].

MIP technology has several theoretical advantages over other array platforms: (1) higher probe specificity and performance, and thus the robustness of genotype and copy number calling; (2) reduced risk of amplification bias and overall cost of the assay, since no PCR amplification is required at the point of mutation detection; (3) greater flexibility in terms of designing MIP probes as signals are assayed using a tag array, hence affording one the choice of using any unique sequence, specific exons or other interesting sequences in the array. MIP arrays 
are therefore particularly well suited to identifying genomic deletions at a very high resolution, for instance at exonic and microsatellite marker level changes [29], and have been reported to work with DNA from FFPE tissue as well $[29,30]$. However, this technology has not yet been extensively tested and the current MIP assay requirement for $2 \mu \mathrm{g}$ test DNA [30] makes this technology prohibitive for samples with limited amounts of DNA available (for example, core biopsies). Currently, a 20,000 SNP platform is commercially available from Affymetrix, but up to 120,000 SNPs can be assayed in a single array.

\section{Solexa Sequencing Technology}

The human genome reference sequence cost an estimated GBP 500 million to produce and an individual human genome analysed today using the Sanger method would cost about GBP 5 million [21]. Further cost reductions are essential before the concept of personalised genome sequencing can be realised. Highly parallel sequencing technologies that can provide both quantitative and qualitative assays of the human genome sequence at a fraction of the cost are being developed $[21,28]$, one of which is the now commercially available Solexa sequencing technology (www.illumina.com).

Solexa sequencing uses 4 proprietary fluorescently labelled modified nucleotides to sequence the millions of clusters of genomic DNA present on a flow cell surface. Following fragmentation, test DNA is ligated to adapters which facilitate the binding of the single-stranded DNA fragments to the flow cell surface. These immobilised DNA fragments serve as sequence templates after which unlabelled nucleotides and enzyme are added to initiate solid-phase bridge amplification. This step creates up to 1,000 identical copies of each template in close proximity (diameter of $1 \mu \mathrm{m}$ or less). The 4 labelled nucleotides (adenine, thymine, guanine and cytosine), which possess a reversible termination property, are then introduced. This allows each cycle of the sequencing reaction to occur simultaneously in the presence of all 4 nucleotides. At the end of each cycle, laser excitation results in emitted fluorescence from each cluster on the flow cell, following which the image is captured. This allows the sequence of bases in a given DNA fragment to be acquired at a single base at a time. Following repeated sequencing cycles, the sequencing data are aligned and compared to reference DNA to identify sequence differences as well as copy number changes for each DNA fragment using a proprietary Genome Analyser software package.

The potential to elucidate the global genomic copy number changes together with all activating and inacti- vating mutations in known oncogenes and tumour suppressor genes, and the presence of translocations and gene fusions, in an entire human tumour genome is a tantalising prospect. From a molecular genetics perspective, this technology has the potential of solving several longstanding controversies, such as the mechanism leading to amplification and rearrangements involved in the genesis of amplified regions. Undeniably, the development of analytical tools and bioinformatics methods to support this type of technology will be a Herculean task. However, when available, these technologies may be the very epitome of the ideal profiling tool for individualised therapy.

\section{Choosing the Right Platform}

To a large extent the choice of platform is then dependent on the type of samples available. The type of samples available for aCGH has a direct impact on the quantity, quality and purity (that is, the proportion of DNA belonging to the cells of interest) of extractable DNA for analysis. The vast majority of translational research studies successfully incorporating aCGH analyses have used fresh-frozen tissues to provide the highest quality nucleic acid for analysis. However, the most widely available resource for DNA remains 'locked' in archival FFPE material, which is accompanied by a wealth of clinical follow-up data. Hence, there are tremendous advantages to be gained if FFPE tissue can be utilised in aCGH studies. However, extracted DNA from FFPE is often heavily cross-linked, degraded and fragmented, heterogeneous (that is, a mix of cells of different genomic composition), and therefore suboptimal for microarray analysis [31]. Consequently, aCGH profiles of FFPE material generally have larger variances, lower intensities and lower dynamic range compared with hybridisations of fresh-frozen tissue and cell line-derived DNA.

Currently, the majority of aCGH studies that have reported success in using DNA extracted from archival FFPE cancers to identify copy number changes and putative therapeutic targets have been based on BAC array platforms [19, 20, 32-34]. Nonetheless, there have recently been limited reports of success in aCGH profiling of FFPE tumours using cDNA arrays $[35,36]$ and Affymetrix [37] array platforms as well. Furthermore, a multiplex PCR-based quality control procedure that can predict the viability of the test DNA for the aCGH analysis has been described [31]. When using FFPE or fresh-frozen tissue for aCGH analysis, the purity of DNA content from tumour tissue can be ensured by careful microdissection of 
tumour from surrounding stromal components. Where tumours are heavily infiltrated with stromal and inflammatory cells, microdissection of tissue in which at least $70-75 \%$ is composed of tumour (or tissue of interest) has been deemed sufficiently pure for aCGH $[10,31,38]$.

With laser capture microdissection, it is now possible to study the genetic features of a limited number of cells or small lesions of interest. The limiting step for coupling laser capture microdissection or other microdissection techniques with aCGH has been the small amount of DNA retrieved using these methods. In the study of tumours where most diagnoses are currently made on core needle biopsies, such as breast cancer, the lack of material can present a significant obstacle to detailed molecular analysis. Although this problem may be circumvented by increasing the yield of DNA for aCGH with whole-genome amplification (WGA) methods [27, 39-45], most WGA methods tested to date induce genomic distortion and introduce significant biases in the analysis. However, the biases induced by some WGA systems seem to be recurrent and can be minimised by using similarly amplified reference and test DNA samples [39, 46].

Evidently, a platform with higher resolution is likely to provide a more comprehensive picture of the global genomic aberrations in a tumour. For example, whilst studies had previously reported DNA amplification at 8p12p11.2 [47] in breast cancer, whose association with prognosis is still contentious, it was only after fine mapping using a high-resolution BAC array that the remarkably complex structure of this amplified region, which is composed of at least 4 distinct amplification cores, emerged [48]. Similar findings have been described for other amplicons in breast cancer, including the recurrent amplification on 20q13 [49]. Clearly, the ease of detecting any particular genomic copy number aberration is inversely proportional to its size (length) and the number of elements involved. Hence, a large $1-\mathrm{Mb}$ region with multiple copy number gains would encompass multiple elements and be detected by most array platforms, whilst a small $20-\mathrm{kb}$ region with only a single-copy number change (for example, microdeletion) would be beyond the resolution of most array platforms, with the possible exception of MIP arrays, SNP arrays and possibly Solexa sequencing. Obviously, cost is also another major consideration, and if high-resolution arrays are unavailable, one might even choose to combine a lower-resolution BAC array for global genomic analysis before fine mapping of an individual chromosome or genomic region of interest using custom-designed oligonucleotide arrays (for example, NimbleGen) [50].
Regardless of resolution, however, some platforms are better at picking up specific anomalies than others. Hence, if a global picture of large-scale gains/amplifications and losses is all that is required, any array platform will suffice, provided it is of the desired resolution. Alternatively, if the detection of more subtle aberrations involving copy number-neutral allelic imbalances such as uniparental disomy and mitotic recombination is required, then SNP arrays or the Solexa sequencing flow cell technology are the platform of choice.

\section{Analysis and Validation}

Analysis of microarray data always poses the statistical problem of false discovery given that thousands of variables (probes/genomic regions) are being investigated using a relatively small number of biological replicates (sample size) due to cost and availability of material [51, 52]. Furthermore, the data cannot be assumed to follow a normal distribution and often many outliers exist. In addition, adjustments need to be made for channel-dependent background, global intensity differences and also to scale the data.

Various analytical tools and methods [53, 54] have been designed to resolve these problems, and numerous bioinformatics software packages designed for the analysis of aCGH data are publicly available from the worldwide web. These include regularly updated versions of the $\mathrm{R}$ data transformation and statistical analysis program (http://www.r-project.org/) and Bio-Conductor (http:// www.bioconductor.org/) [55]. In addition, all commercially available aCGH platforms come with their own specific data analysis software (for example, Illumina Beadstudio and QuantiSNP) [56], including platformspecific protocols for data normalisation and bioinformatics support. Essentially, these analytical software packages use algorithms to reduce the experimental variation for regions with similar copy numbers (that is, smoothing algorithms), such as adaptative weighted smoothing [57], maximum likelihood models, hidden Markov models [58], or row Loess methods [59] and Gaussian smoothing [60], before confidently defining genomic changes. In simplistic terms, these analytical methods transform aCGH data by organising a user-defined consecutive sequence of adjacent signals into regions of constant copy number known as segments, which are subsequently classified as a gain, a loss or no change depending on their signal intensities.
68

Pathobiology 2008;75:63-74
Tan/Reis-Filho 
Whichever methods utilised in the analysis of aCGH data, it is vitally important that the invariably and often excessively large volume of data generated is appropriately curated and validated with in situ or other molecular methods. These include quantitative real-time PCR techniques [61] and fluorescent in situ hybridisation, chromogenic in situ hybridisation or silver in situ hybridisation [19, 62-66]. Additionally, in studies where matched normal DNA samples are not available, regions of genomic regions of interest (that is, recurrently amplified or deleted) need to be cross-referenced with available germline DNA copy number polymorphism databases [67] and validated, preferentially, with in situ methods.

\section{Finding the Target}

Fundamental to any good experimental study is good design. With the extensive dimensionality of data generated by aCGH studies, good design has never been more crucial in facilitating data analysis and appropriate interpretation of results [10]. When designing microarray studies, there are 3 commonly adopted approaches, namely class comparison, class discovery or class prediction studies [22]. In addition, aCGH is also often employed in descriptive molecular genetic characterisation of tumours and accurate identification of the boundaries of specific amplicons and deleted regions [10, 18, 19, 64]. Although the majority of microarray-based gene expression and aCGH studies in breast cancer have employed one of the above approaches [40,68-72], this review will focus on the how aCGH can be used for the identification of potentially 'druggable', recurrent molecular genetic changes.

This challenge of using aCGH as a screening tool for the identification of therapeutic targets is not trivial. Our group and others have approached this challenge in 2 distinct ways, that is, as top-down and bottom-up studies (fig. 1, 2). The top-down approach involves profiling a group of histopathologically homogenous tumours using aCGH to identify recurrent genetic changes that may harbour potential oncogenes or tumour suppressor genes. Here, the emphasis is on discovering individual genetic aberrations and the genes mapping to these regions that have a significant impact on tumour biology. For example, in oestrogen receptor-positive cancers, recurrent amplifications of 8p11.2-8p12 are observed in approximately $10 \%$ of cases. Array CGH can be used to define the boundaries of this amplicon and the genes that map to the smallest region of amplification (SRA, that is, the ge-

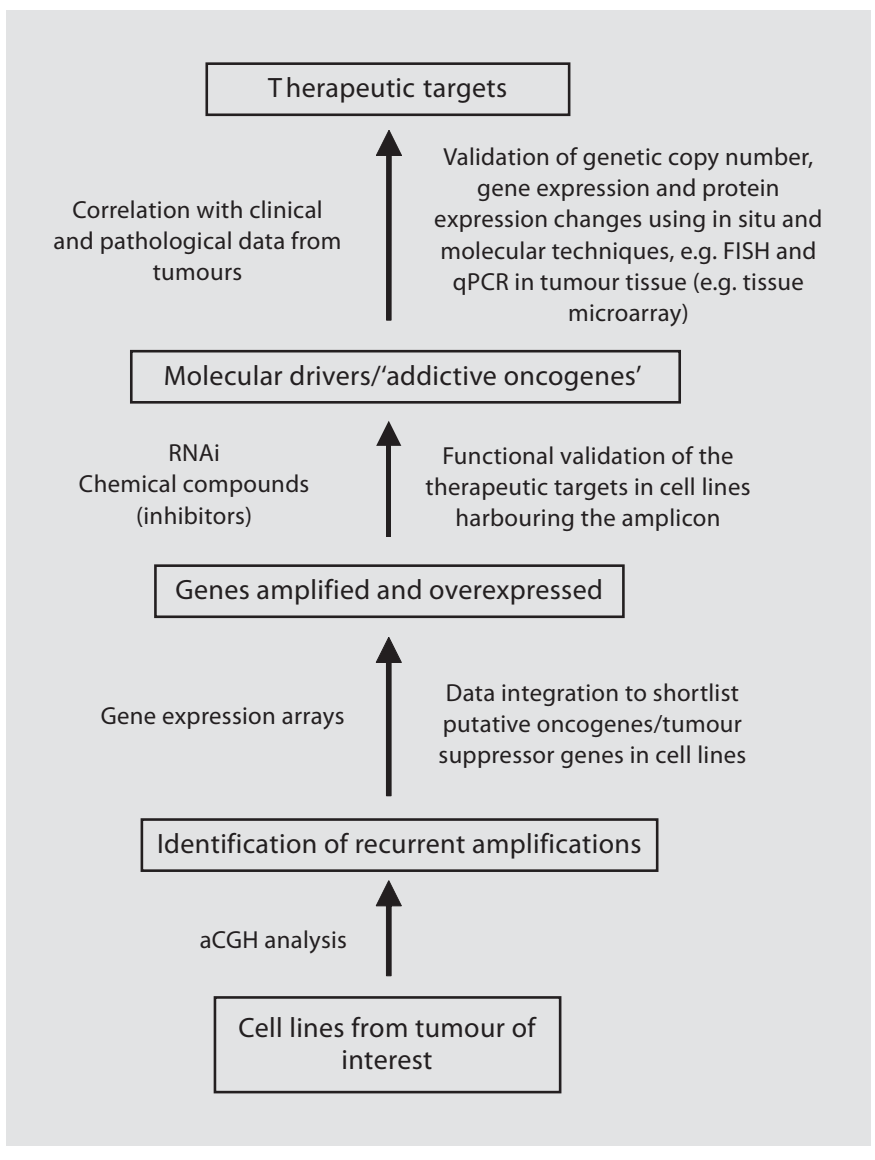

Fig. 1. Schematic diagram of bottom-up approach for the identification of therapeutic targets based on aCGH analysis. qPCR = Quantitative real-time PCR.

nomic region that is amplified in all cases harbouring the amplification). It should be noted that with the increasing resolution of aCGH, it has become apparent that most amplicons are much more complex than previously anticipated and that these amplicons may comprise more than 1 SRA and more than 1 amplicon driver. Both concepts have recently been demonstrated in breast tumours with amplification of 8p11.2-8p12 [48], where at least 4 distinct amplicon cores have been described, and the 2 prognostically distinct patterns of 20q13 amplification [49] with differing gene expression profiles that have been identified in breast cancers.

Apart from detailed and diligent aCGH analysis, this process requires overlaying of array $\mathrm{CGH}$ and expression array data (or another type of relatively high-throughput expression profiling), protein profiling or RNA interference analysis. If the expression of the genes mapping to 
Fig. 2. Schematic diagram of top-down approach for the identification of therapeutic targets based on aCGH analysis. qPCR = Quantitative real-time PCR.

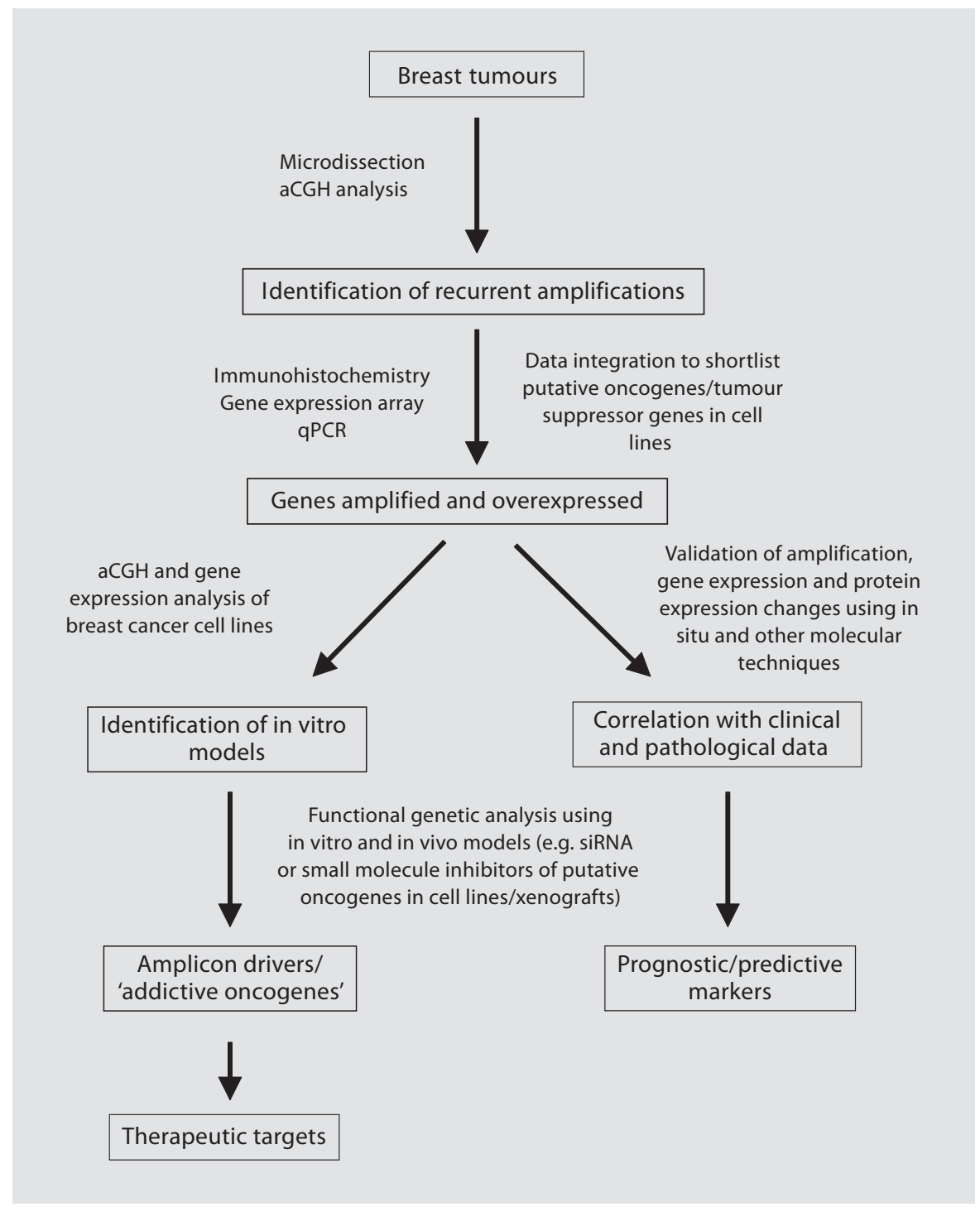

the SRA is determined in the same tumours by means of expression arrays, quantitative real-time PCR or immunohistochemistry (if antibodies for all genes are available), the genes whose expressions correlate with amplification can be identified. However, one should bear in mind that for some genes, expression is more pervasive than gene amplification and correlation coefficients may not be as high as expected. Therefore, ruling out a gene as a possible amplicon driver based on a low correlation coefficient may risk excluding potentially, biologically interesting genes or even the actual amplicon driver. One study ruled out many genes as possible amplicon drivers of 8p11.2-8p12, including FGFR1, based on that approach [73]. We advocate a more cautionary approach, ruling out only those genes that are not expressed when their locus is amplified. Given the complexity of the amplicons, this should be based on a diligent overlaying of genomic and expression data, including the complexity of the amplicon cores [48].

After identifying a specific amplicon and its possible/ likely driver(s), the next step is to identify a model to test whether cancer cells of similar phenotype depend on any of those genes for their survival (that is, if the genes to be studied would elicit an oncogene addiction phenomenon in a specific model that resembles the cancer initially studied). The identification of the model can be achieved either by a detailed profiling of cancer cell lines or by interrogating publicly available datasets of genomic and ex- 
pression data of specific cell lines similar to the type of tumour that was studied (for example, Neve et al. [74] for breast cancer cell lines). It is of utmost importance to identify models that not only harbour the amplicon of interest, but also have a phenotype that is similar to that of the cancer studied. Unlike previous beliefs that cancer cell lines would have so many in vitro artefacts that could not be used as models for human cancer, recent studies have provided strong circumstantial evidence to suggest that not only the phenotypes of tumours are recapitulated in cell lines, but also many of the genomic aberrations identified by aCGH analysis of human tumours are found in the genomic profiles of cell lines [74-76]. For instance, up to $10 \%$ of luminal cancers harbour 8 p11.28 p12 and 11q13.3 co-amplifications [19, 77] and 2 breast cancer cell lines of luminal phenotype also harbour the same co-amplification (that is, MDA-MB-134 and SUM44) [19, 74]; a subgroup of basal-like breast cancers harbour amplification of the EGFR gene $[17,19]$ and 2 basal-like breast cancer cell lines also harbour this amplification (that is, MDA-MB-468 and BT-20) $[19,74]$ and the amplicons are remarkably similar [Reis-Filho, pers. commun.]. Once the model has been identified, the biological significance of each gene can be tested by knocking it down using RNA interference methods and by means of chemical inhibition, if the protein product of the gene can be targeted with compounds already available. This approach has led to the identification of putative therapeutic targets in various tumours such as E2F3 in bladder cancer [78], RAB25 in breast and ovarian cancer [18], IGF1R in Wilms' tumours [64] and FGFR1 in breast cancer [19].

The bottom-up approach involves the identification of possible therapeutic targets in cell lines of a particular cancer type and then identifying a group of tumours with similar phenotypic characteristics that harbour the same genomic changes. For example, by subjecting a set of cell lines to both aCGH and gene expression array analysis, putative oncogene candidates within a validated region of recurrent amplification can be interrogated at the level of gene expression to identify a shortlist of genes where a good correlation exists between amplification and mRNA overexpression [10, 74]. From this shortlist, Western blots are carried out on cell line lysates to confirm the presence of protein overexpression and its correlation with mRNA expression, whilst parallel immunohistochemical analysis in a larger series of FFPE tissues can be performed to confirm the presence of overexpression of the protein(s) of interest in tumours. The prognostic and predictive significance of these proteins, and their association with his-

Comparative Genomic Hybridisation

Arrays topathological subtype, will also provide a further layer of evidence with regards to phenotypic relevance. The goal of the analysis of the cell lines is to generate a shortlist of genes which are amplified and overexpressed and that can be then tested in clinical samples to determine whether they are either of prognostic significance or putative therapeutic targets or both. For example, the analysis of HER2-amplified breast cancer cell lines has demonstrated that other genes pertaining to the HER 2 amplicon, such as GRB7 and $S T A R D 3$, are also consistently overexpressed when amplified. When these genes were knocked down with short-interfering RNA (siRNA), significantly decreased cell proliferation and cell cycle progression were observed [79]. These findings provide circumstantial evidence that HER2-amplified cell lines may also be addicted to the signalling of genes co-amplified together with HER2. Tumour DNA can then be subjected to gene sequencing to look for mutations of functionally significant genes as well.

Clearly, the type and number of samples available will affect the feasibility of any of the aforementioned approaches, in particular if a top-down or a bottom-up approach would be more suitable. Where fresh-frozen tumour samples are unavailable and FFPE DNA is not of sufficient quality for aCGH analysis, a bottom-up approach is more likely to be fruitful. Conversely, even with fresh-frozen tissue available, comprehensive molecular genetic profiling of cell lines derived from the tumour subtype of interest also has the added advantage of providing investigators with the optimal models for in vitro functional assays [74].

\section{Data Integration}

One of the challenges of the approaches outlined above is how to define a shortlist of the most likely therapeutic targets. In this respect, integrative analysis of highthroughput data [80-83] from aCGH, gene expression and methylation arrays and proteomic analysis may be particularly useful for several reasons: (1) the impact of methodological unreliability is reduced by cross-validation between data from different biological (that is, genomic, gene transcription or protein expression) levels; (2) integration of genomic data (that is, copy number changes) with data subject to dynamic changes (such as mRNA and protein expression); (3) facilitate the development of a systems biology approach to delineate the interplay between key signalling pathways, networks and regulatory feedback loops that determine disease phenotype. However, such integrative approaches are encum- 
bered by complex logistic and analytical challenges, which include: (1) the immense biological complexity in progressing from genotype to phenotype; (2) sources of variation and functional redundancy within each biological level [82] that exist for any individual, set against the background of patient and tumour heterogeneity; (3) the ever increasing need for sufficient bioinformatics expertise, software and hardware to process vast amounts of data generated by these integrative studies; (4) limited availability of clinical material (such as core biopsies) for use in different assays. Furthermore, most systems have not incorporated all levels of complexity; for instance, microRNA (miRNA) data have been largely neglected in most models of data integration.

In addition, such models, in particular in the bottomup approach, may be superseded by the results of overlaying aCGH data with genome-wide siRNA screening of specific cell line models. Integrating genomic changes with high-throughput siRNA screening may lead to the identification of amplified genes whose siRNA inhibition is lethal and may expedite the identification of oncogenes fundamental for the survival of cancer cells.

\section{Conclusions}

The promise of aCGH needs to be tempered by the reality that it currently remains a crude, albeit powerful, screening tool, and should be used as an adjunct to other molecular techniques. The identification of novel amplicons and tumour suppressor genes [18, 64, 65, 84] has undoubtedly been expedited by aCGH, but this is only a small step forward in unravelling the complexity of cancer. Indeed, the vogue is an integrative, systems biology approach $[80,81]$ where results from aCGH, gene expression analysis and functional assays are combined to facilitate our understanding of complex biological systems, and serve as a basis for the identification of future therapeutic strategies and targets in breast cancer. Furthermore, combining genome-wide aCGH with genome-wide siRNA or shRNA screening holds key for a more objective identification of novel therapeutic targets.

\section{References}

1 Weinstein IB: Cancer: addiction to oncogenes - the Achilles heal of cancer. Science 2002;297:63-64.

2 Weinstein IB, Joe AK: Mechanisms of disease: oncogene addiction - a rationale for molecular targeting in cancer therapy. Nat Clin Pract Oncol 2006;3:448-457.

-3 Hanahan D, Weinberg RA: The hallmarks of cancer. Cell 2000;100:57-70.

4 Weinstein IB: Disorders in cell circuitry during multistage carcinogenesis: the role of homeostasis. Carcinogenesis 2000;21:857864.

5 Felsher DW, Bishop JM: Reversible tumorigenesis by MYC in hematopoietic lineages. Mol Cell 1999;4:199-207.

-6 Kantarjian HM, Giles F, Quintas-Cardama A, Cortes J: Important therapeutic targets in chronic myelogenous leukemia. Clin Cancer Res 2007;13:1089-1097.

7 Lohrisch C, Piccart M: An overview of HER2. Semin Oncol 2001;28:3-11.

8 Hoglund M, Gisselsson D, Sall T, Mitelman F: Coping with complexity: multivariate analysis of tumor karyotypes. Cancer Genet Cytogenet 2002;135:103-109.

-9 Kallioniemi A, Kallioniemi OP, Sudar D, Rutovitz D, Gray JW, Waldman F, Pinkel D: Comparative genomic hybridization for molecular cytogenetic analysis of solid tumors. Science 1992;258:818-821.
10 Tan DS, Lambros MB, Natrajan R, Reis-Filho JS: Getting it right: designing microarray (and not 'microawry') comparative genomic hybridization studies for cancer research. Lab Invest 2007;87:737-754.

11 Oostlander AE, Meijer GA, Ylstra B: Microarray-based comparative genomic hybridization and its applications in human genetics. Clin Genet 2004;66:488-495.

12 Ylstra B, van den Ijssel P, Carvalho B, Brakenhoff RH, Meijer GA: BAC to the future! or oligonucleotides: a perspective for micro array comparative genomic hybridization (array CGH). Nucleic Acids Res 2006;34: 445-450.

13 Jong K, Marchiori E, van der Vaart A, Chin SF, Carvalho B, Tijssen M, Eijk PP, van den Ijssel P, Grabsch H, Quirke P, Oudejans JJ, Meijer GA, Caldas C, Ylstra B: Cross-platform array comparative genomic hybridization meta-analysis separates hematopoietic and mesenchymal from epithelial tumors. Oncogene 2007;26:1499-1506.

14 Bergamaschi A, Kim YH, Wang P, Sorlie T, Hernandez-Boussard T, Lonning PE, Tibshirani R, Borresen-Dale AL, Pollack JR: Distinct patterns of DNA copy number alteration are associated with different clinicopathological features and gene-expression subtypes of breast cancer. Genes Chromosomes Cancer 2006;45:1033-1040.
15 Tanami H, Tsuda H, Okabe S, Iwai T, Sugihara K, Imoto I, Inazawa J: Involvement of cyclin D3 in liver metastasis of colorectal cancer, revealed by genome-wide copy-number analysis. Lab Invest 2005;85:1118-1129.

16 Reis-Filho JS, Simpson PT, Gale T, Lakhani SR: The molecular genetics of breast cancer: the contribution of comparative genomic hybridization. Pathol Res Pract 2005;201:713725 .

17 Reis-Filho JS, Simpson PT, Jones C, Steele D, Mackay A, Iravani M, Fenwick K, Valgeirsson $\mathrm{H}$, Lambros M, Ashworth A, Palacios J, Schmitt F, Lakhani SR: Pleomorphic lobular carcinoma of the breast: role of comprehensive molecular pathology in characterization of an entity. J Pathol 2005;207:1-13.

18 Cheng KW, Lahad JP, Kuo WL, Lapuk A, Yamada K, Auersperg N, Liu J, Smith-McCune K, Lu KH, Fishman D, Gray JW, Mills GB: The RAB25 small GTPase determines aggressiveness of ovarian and breast cancers. Nat Med 2004;10:1251-1256.

19 Reis-Filho JS, Simpson PT, Turner NC, Lambros MB, Jones C, Mackay A, Grigoriadis A, Sarrio D, Savage K, Dexter T, Iravani M, Fenwick K, Weber B, Hardisson D, Schmitt FC, Palacios J, Lakhani SR, Ashworth A: FGFR1 emerges as a potential therapeutic target for lobular breast carcinomas. Clin Cancer Res 2006;12:6652-6662. 
20 Reis-Filho JS, Pinheiro C, Lambros MB, Milanezi F, Carvalho S, Savage K, Simpson PT, Jones C, Swift S, Mackay A, Reis RM, Hornick JL, Pereira EM, Baltazar F, Fletcher CD, Ashworth A, Lakhani SR, Schmitt FC: EGFR amplification and lack of activating mutations in metaplastic breast carcinomas. J Pathol 2006;209:445-453.

21 Bentley DR: Whole-genome re-sequencing. Curr Opin Genet Dev 2006;16:545-552.

-22 Simon R, Radmacher MD, Dobbin K, McShane LM: Pitfalls in the use of DNA microarray data for diagnostic and prognostic classification. J Natl Cancer Inst 2003;95:1418.

23 Pinkel D, Albertson DG: Array comparative genomic hybridization and its applications in cancer. Nat Genet 2005;37(suppl):S11S17.

24 Pollack JR, Perou CM, Alizadeh AA, Eisen $\mathrm{MB}$, Pergamenschikov A, Williams CF, Jeffrey SS, Botstein D, Brown PO: Genomewide analysis of DNA copy-number changes using cDNA microarrays. Nat Genet 1999; 23:41-46.

25 Lockwood WW, Chari R, Chi B, Lam WL: Recent advances in array comparative genomic hybridization technologies and their applications in human genetics. Eur J Hum Genet 2006;14:139-148.

-26 Johnson NA, Hamoudi RA, Ichimura K, Liu L, Pearson DM, Collins VP, Du MQ: Application of array CGH on archival formalinfixed paraffin-embedded tissues including small numbers of microdissected cells. Lab Invest 2006;86:968-978.

-27 Little SE, Vuononvirta R, Reis-Filho JS, Natrajan $\mathrm{R}$, Iravani $\mathrm{M}$, Fenwick $\mathrm{K}$, Mackay A, Ashworth A, Pritchard-Jones K, Jones C: Array CGH using whole genome amplification of fresh-frozen and formalin-fixed, paraffin-embedded tumor DNA. Genomics 2006; 87:298-306.

-28 Fan JB, Chee MS, Gunderson KL: Highly parallel genomic assays. Nat Rev Genet 2006; 7:632-644.

-29 Ji H, Kumm J, Zhang M, Farnam K, Salari K, Faham M, Ford JM, Davis RW: Molecular inversion probe analysis of gene copy alterations reveals distinct categories of colorectal carcinoma. Cancer Res 2006;66:7910-7919.

-30 Wang Y, Moorhead M, Karlin-Neumann G, Falkowski M, Chen C, Siddiqui F, Davis RW, Willis TD, Faham M: Allele quantification using molecular inversion probes (MIP). Nucleic Acids Res 2005;33:e183.

- 31 van Beers EH, Joosse SA, Ligtenberg MJ, Fles R, Hogervorst FB, Verhoef S, Nederlof PM: A multiplex PCR predictor for aCGH success of FFPE samples. Br J Cancer 2006;94:333337.

- 32 Baldwin C, Garnis C, Zhang L, Rosin MP, Lam WL: Multiple microalterations detected at high frequency in oral cancer. Cancer Res 2005;65:7561-7567.
3 Nessling M, Richter K, Schwaenen C, Roerig P, Wrobel G, Wessendorf S, Fritz B, Bentz M, Sinn HP, Radlwimmer B, Lichter P: Candidate genes in breast cancer revealed by $\mathrm{mi}^{-}$ croarray-based comparative genomic hybridization of archived tissue. Cancer Res 2005;65:439-447.

- 34 van Dekken H, Paris PL, Albertson DG, Alers JC, Andaya A, Kowbel D, van der Kwast TH, Pinkel D, Schroder FH, Vissers KJ, Wildhagen MF, Collins C: Evaluation of genetic patterns in different tumor areas of intermediate-grade prostatic adenocarcinomas by high-resolution genomic array analysis. Genes Chromosomes Cancer 2004; 39:249-256.

35 Harvell JD, Kohler S, Zhu S, HernandezBoussard T, Pollack JR, van de Rijn M: Highresolution array-based comparative genomic hybridization for distinguishing paraffinembedded Spitz nevi and melanomas. Diagn Mol Pathol 2004;13:22-25.

36 Linn SC, West RB, Pollack JR, Zhu S, Hernandez-Boussard T, Nielsen TO, Rubin BP, Patel R, Goldblum JR, Siegmund D, Botstein D, Brown PO, Gilks CB, van de Rijn M: Gene expression patterns and gene copy number changes in dermatofibrosarcoma protuberans. Am J Pathol 2003;163:2383-2395.

37 Thompson ER, Herbert SC, Forrest SM, Campbell IG: Whole genome SNP arrays using DNA derived from formalin-fixed, paraffin-embedded ovarian tumor tissue. Hum Mutat 2005;26:384-389.

-38 Weiss MM, Hermsen MA, Meijer GA, van Grieken NC, Baak JP, Kuipers EJ, van Diest PJ: Comparative genomic hybridisation. Mol Pathol 1999;52:243-251.

- 39 Arriola E, Lambros MB, Jones C, Dexter T, Mackay A, Tan DS, Tamber N, Fenwick K, Ashworth A, Dowsett M, Reis-Filho JS: Evaluation of Phi29-based whole-genome amplification for microarray-based comparative genomic hybridisation. Lab Invest 2007;87: 75-83.

40 Raponi M, Zhang Y, Yu J, Chen G, Lee G, Taylor JM, Macdonald J, Thomas D, Moskaluk C, Wang Y, Beer DG: Gene expression signatures for predicting prognosis of squamous cell and adenocarcinomas of the lung. Cancer Res 2006;66:7466-7472.

41 Pirker C, Raidl M, Steiner E, Elbling L, Holzmann K, Spiegl-Kreinecker S, Aubele M, Grasl-Kraupp B, Marosi C, Micksche M, Berger W: Whole genome amplification for CGH analysis: Linker-adapter PCR as the method of choice for difficult and limited samples. Cytometry A 2004;61:26-34.

42 Tanabe C, Aoyagi K, Sakiyama T, Kohno T, Yanagitani N, Akimoto S, Sakamoto M, Sakamoto H, Yokota J, Ohki M, Terada M, Yoshida T, Sasaki H: Evaluation of a wholegenome amplification method based on adaptor-ligation PCR of randomly sheared genomic DNA. Genes Chromosomes Cancer 2003;38:168-176.
43 Fiegler H, Geigl JB, Langer S, Rigler D, Porter K, Unger K, Carter NP, Speicher MR: High resolution array-CGH analysis of single cells. Nucleic Acids Res 2007;35:e15.

44 Aviel-Ronen S, Qi Zhu C, Coe BP, Liu N, Watson SK, Lam WL, Tsao MS: Large fragment Bst DNA polymerase for whole genome amplification of DNA from formalin-fixed paraffin-embedded tissues. BMC Genomics 2006;7:312.

45 Lovmar L, Syvanen AC: Multiple displacement amplification to create a long-lasting source of DNA for genetic studies. Hum $\mathrm{Mu}$ tat 2006;27:603-614.

46 Lage JM, Leamon JH, Pejovic T, Hamann S, Lacey M, Dillon D, Segraves R, Vossbrinck B, Gonzalez A, Pinkel D, Albertson DG, Costa J, Lizardi PM: Whole genome analysis of genetic alterations in small DNA samples using hyperbranched strand displacement amplification and array-CGH. Genome Res 2003; 13:294-307.

-47 Courjal F, Cuny M, Simony-Lafontaine J, Louason G, Speiser P, Zeillinger R, Rodriguez C, Theillet C: Mapping of DNA amplifications at 15 chromosomal localizations in 1,875 breast tumors: definition of phenotypic groups. Cancer Res 1997;57:4360-4367.

-48 Gelsi-Boyer V, Orsetti B, Cervera N, Finetti $\mathrm{P}$, Sircoulomb F, Rouge C, Lasorsa L, Letessier A, Ginestier C, Monville F, Esteyries S, Adelaide J, Esterni B, Henry C, Ethier SP, Bibeau F, Mozziconacci MJ, Charafe-Jauffret E, Jacquemier J, Bertucci F, Birnbaum D, Theillet C, Chaffanet M: Comprehensive profiling of 8p11-12 amplification in breast cancer. Mol Cancer Res 2005;3:655-667.

-49 Ginestier C, Cervera N, Finetti P, Esteyries S, Esterni B, Adelaide J, Xerri L, Viens P, Jacquemier J, Charafe-Jauffret E, Chaffanet M, Birnbaum D, Bertucci F: Prognosis and gene expression profiling of 20q13-amplified breast cancers. Clin Cancer Res 2006;12: 4533-4544.

50 Natrajan R, Williams RD, Grigoriadis A, Mackay A, Fenwick K, Ashworth A, Dome JS, Grundy PE, Pritchard-Jones K, Jones C: Delineation of a $1 \mathrm{Mb}$ breakpoint region at $1 \mathrm{p} 13$ in Wilms tumors by fine-tiling oligonucleotide array CGH. Genes Chromosomes Cancer 2007;46:607-615.

51 Dobbin K, Simon R: Sample size determination in microarray experiments for class comparison and prognostic classification. Biostatistics 2005;6:27-38.

52 Ein-Dor L, Zuk O, Domany E: Thousands of samples are needed to generate a robust gene list for predicting outcome in cancer. Proc Natl Acad Sci USA 2006;103:5923-5928.

53 Simon R: Roadmap for developing and validating therapeutically relevant genomic classifiers. J Clin Oncol 2005;23:7332-7341.

-54 Pawitan Y, Murthy KR, Michiels S, Ploner A: Bias in the estimation of false discovery rate in microarray studies. Bioinformatics 2005; 21:3865-3872. 
55 Paris PL, Andaya A, Fridlyand J, Jain AN, Weinberg V, Kowbel D, Brebner JH, Simko J, Watson JE, Volik S, Albertson DG, Pinkel D, Alers JC, van der Kwast TH, Vissers KJ, Schroder FH, Wildhagen MF, Febbo PG, Chinnaiyan AM, Pienta KJ, Carroll PR, Rubin MA, Collins C, van Dekken H: Whole genome scanning identifies genotypes associated with recurrence and metastasis in prostate tumors. Hum Mol Genet 2004; 13: 1303-1313.

- 56 Colella S, Yau C, Taylor JM, Mirza G, Butler $\mathrm{H}$, Clouston P, Bassett AS, Seller A, Holmes CC, Ragoussis J: QuantiSNP: an Objective Bayes Hidden-Markov Model to detect and accurately map copy number variation using SNP genotyping data. Nucleic Acids Res 2007;35:2013-2025.

57 Hupe P, Stransky N, Thiery JP, Radvanyi F, Barillot E: Analysis of array CGH data: from signal ratio to gain and loss of DNA regions. Bioinformatics 2004;20:3413-3422.

58 Shah SP, Xuan X, DeLeeuw RJ, Khojasteh M, Lam WL, Ng R, Murphy KP: Integrating copy number polymorphisms into array CGH analysis using a robust HMM. Bioinformatics 2006;22:e431-e439.

-59 Yang YH, Dudoit S, Luu P, Lin DM, Peng V, Ngai J, Speed TP: Normalization for cDNA microarray data: a robust composite method addressing single and multiple slide systematic variation. Nucleic Acids Res 2002;30: e15.

60 van Beers EH, Nederlof PM: Array-CGH and breast cancer. Breast Cancer Res 2006;8: 210.

61 Ginzinger DG: Gene quantification using real-time quantitative PCR: an emerging technology hits the mainstream. Exp Hematol 2002;30:503-512.

-62 Di Palma S, Lambros MB, Savage K, Jones C, Mackay A, Dexter T, Iravani M, Fenwick K, Ashworth A, Reis-Filho JS: Oncocytic change in pleomorphic adenoma: molecular evidence in support of an origin in neoplastic cells. J Clin Pathol 2007;60:492-499.

63 Lambros MB, Simpson PT, Jones C, Natrajan R, Westbury C, Steele D, Savage K, Mackay A, Schmitt FC, Ashworth A, Reis-Filho JS: Unlocking pathology archives for molecular genetic studies: a reliable method to generate probes for chromogenic and fluorescent in situ hybridization. Lab Invest 2006;86:398408.

64 Natrajan R, Reis-Filho JS, Little SE, Messahel B, Brundler MA, Dome JS, Grundy PE, Vujanic GM, Pritchard-Jones K, Jones C: Blastemal expression of type I insulin-like growth factor receptor in Wilms' tumors is driven by increased copy number and correlates with relapse. Cancer Res 2006;66: 11148-11155.
65 Natrajan R, Little SE, Reis-Filho JS, Hing L, Messahel B, Grundy PE, Dome JS, Schneider T, Vujanic GM, Pritchard-Jones K, Jones C: Amplification and overexpression of CACNA1E correlates with relapse in favorable histology Wilms' tumors. Clin Cancer Res 2006;12:7284-7293.

66 Vincent-Salomon A, Gruel N, Lucchesi C, Mac Grogan G, Dendale R, Sigal-Zafrani B, Longy M, Raynal V, Pierron G, de Mascarel I, Taris C, Stoppa-Lyonnet D, Pierga JY, Salmon R, Sastre-Garau X, Fourquet A, Delattre O, de Cremoux P, Aurias A: Identification of typical medullary breast carcinoma as a genomic sub-group of basal-like carcinomas, a heterogeneous new molecular entity. Breast Cancer Res 2007;9:R24.

67 Carter NP: Methods and strategies for analyzing copy number variation using DNA microarrays. Nat Genet 2007;39:S16-S21.

68 Loo LW, Grove DI, Williams EM, Neal CL, Cousens LA, Schubert EL, Holcomb IN, Massa HF, Glogovac J, Li CI, Malone KE, Daling JR, Delrow JJ, Trask BJ, Hsu L, Porter PL: Array comparative genomic hybridization analysis of genomic alterations in breast cancer subtypes. Cancer Res 2004;64:85418549.

69 Perou CM, Sorlie T, Eisen MB, van de Rijn M, Jeffrey SS, Rees CA, Pollack JR, Ross DT, Johnsen H, Akslen LA, Fluge O, Pergamenschikov A, Williams C, Zhu SX, Lonning PE, Borresen-Dale AL, Brown PO, Botstein D: Molecular portraits of human breast tumours. Nature 2000;406:747-752.

-70 Pierga JY, Reis-Filho JS, Cleator SJ, Dexter T, Mackay A, Simpson P, Fenwick K, Iravani M, Salter J, Hills M, Jones C, Ashworth A, Smith IE, Powles T, Dowsett M: Microarray-based comparative genomic hybridisation of breast cancer patients receiving neoadjuvant chemotherapy. Br J Cancer 2007;96:341-351.

71 Stange DE, Radlwimmer B, Schubert F, Traub F, Pich A, Toedt G, Mendrzyk F, Lehmann U, Eils R, Kreipe H, Lichter P: Highresolution genomic profiling reveals association of chromosomal aberrations on $1 \mathrm{q}$ and $16 \mathrm{p}$ with histologic and genetic subgroups of invasive breast cancer. Clin Cancer Res 2006; 12:345-352.

72 van de Vijver MJ, He YD, van't Veer LJ, Dai H, Hart AA, Voskuil DW, Schreiber GJ, Peterse JL, Roberts C, Marton MJ, Parrish M, Atsma D, Witteveen A, Glas A, Delahaye L, van der Velde T, Bartelink H, Rodenhuis S, Rutgers ET, Friend SH, Bernards R: A geneexpression signature as a predictor of survival in breast cancer. N Engl J Med 2002;347: 1999-2009.

73 Garcia MJ, Pole JC, Chin SF, Teschendorff A, Naderi A, Ozdag H, Vias M, Kranjac T, Subkhankulova T, Paish C, Ellis I, Brenton JD, Edwards PA, Caldas C: A $1 \mathrm{Mb}$ minimal amplicon at 8 p11-12 in breast cancer identifies new candidate oncogenes. Oncogene 2005; 24:5235-5245.
74 Neve RM, Chin K, Fridlyand J, Yeh J, Baehner FL, Fevr T, Clark L, Bayani N, Coppe JP, Tong F, Speed T, Spellman PT, DeVries S, Lapuk A, Wang NJ, Kuo WL, Stilwell JL, Pinkel D, Albertson DG, Waldman FM, McCormick F, Dickson RB, Johnson MD, Lippman M, Ethier S, Gazdar A, Gray JW: A collection of breast cancer cell lines for the study of functionally distinct cancer subtypes. Cancer Cell 2006;10:515-527.

75 Jonsson G, Staaf J, Olsson E, Heidenblad M, Vallon-Christersson J, Osoegawa K, de Jong P, Oredsson S, Ringner M, Hoglund M, Borg A: High-resolution genomic profiles of breast cancer cell lines assessed by tiling BAC array comparative genomic hybridization. Genes Chromosomes Cancer 2007;46: 543-558.

76 Greshock J, Nathanson K, Martin AM, Zhang L, Coukos G, Weber BL, Zaks TZ: Cancer cell lines as genetic models of their parent histology: analyses based on array comparative genomic hybridization. Cancer Res 2007;67:3594-3600.

77 Elbauomy Elsheikh S, Green AR, Lambros MB, Turner NC, Grainge MJ, Powe D, Ellis IO, Reis-Filho JS: FGFR1 amplification in breast carcinomas: a chromogenic in situ hybridisation analysis. Breast Cancer Res 2007; 9:R23.

78 Feber A, Clark J, Goodwin G, Dodson AR, Smith PH, Fletcher A, Edwards S, Flohr P, Falconer A, Roe T, Kovacs G, Dennis N, Fisher C, Wooster R, Huddart R, Foster CS, Cooper CS: Amplification and overexpression of E2F3 in human bladder cancer. Oncogene 2004;23:1627-1630.

79 Kao J, Pollack JR: RNA interference-based functional dissection of the 17q12 amplicon in breast cancer reveals contribution of coamplified genes. Genes Chromosomes Cancer 2006;45:761-769.

80 Bosl WJ: Systems biology by the rules: hybrid intelligent systems for pathway modeling and discovery. BMC Syst Biol 2007;1:13.

81 Hornberg JJ, Bruggeman FJ, Westerhoff HV, Lankelma J: Cancer: a systems biology disease. Biosystems 2006;83:81-90.

82 Reif DM, White BC, Moore JH: Integrated analysis of genetic, genomic and proteomic data. Expert Rev Proteomics 2004;1:67-75.

83 Greenbaum D, Jansen R, Gerstein M: Analysis of mRNA expression and protein abundance data: an approach for the comparison of the enrichment of features in the cellular population of proteins and transcripts. Bioinformatics 2002;18:585-596.

84 Rivera MN, Kim WJ, Wells J, Driscoll DR, Brannigan BW, Han M, Kim JC, Feinberg AP, Gerald WL, Vargas SO, Chin L, Iafrate AJ, Bell DW, Haber DA: An X chromosome gene, WTX, is commonly inactivated in Wilms tumor. Science 2007;315:642-645. 